\title{
An Unusual Case of Monozygotic Epigastric Heteropagus Twinning
}

\author{
By Eui Ho Hwang, Seok Joo Han, Jin-Sung Lee, and Myo Kyung Lee \\ Seoul, Korea
}

\begin{abstract}
- Epigastric heteropagus refers to unequal and asymmetric conjoined twins in which the dependent component (parasite) is smaller and usually attached to the epigastrium of the dominant component (autosite). Epigastric heteropagus is a very rare type of conjoined twins. It is generally assumed that conjoined twins represent a form of monozygotic twinning, but there has been no confirmation of this monozygotic hypothesis. Epigastric heteropagus twins differ in several ways from symmetrical conjoined twins. These include male preponderance, and no major connection of vessels, bowels, or bones. These significant characteristics suggest to the authors that the fusion of two fertilized ova and the atrophy of one fetus resulted in this interesting malformation. However, a DNA study indicated monozygotic origin in their case. The possible pathogenesis was ischemic atrophy of the body structure of the monozygotic conjoined twins at an early gestational age.

Copyright 1996 by W.B. Saunders Company
\end{abstract}

INDEX WORDS: Conjoined twins, epigastric heteropagus, monozygotic; DNA study.

C ONJOINED TWINS are one of the rarest congenital abnormalities. They occur once in every 50,000 to 100,000 births. Conjoined twins are classified as symmetrical or asymmetrical. The asymmetrical form is known as heteropagus. ${ }^{1}$ With heteropagus cases, the dependent portion (parasite) is smaller than the host (autosite). Epigastric heteropagus refers to the conjoined twin in which the parasite is attached to the epigastrium of the autosite. There are only nine similar cases in the English-language literature. ${ }^{1-9}$

\section{CASE REPORT}

A male boy with a conjoined twin was referred to our hospital on the day of birth. His birth history consisted of a normal spontaneous vaginal delivery after 40 weeks of uncomplicated gestation. The mother was 34 years old (gravida 3, para 3). The first baby had syndactyly of one hand. No other congenital abnormality had been documented in the patient's family history.

\section{Clinical Presentation}

The parasite was attached to the epigastrium of the autosite above an omphalocele. The autosite was active and appeared normal except for the omphalocele. The combined birth weight was $3,700 \mathrm{~g}$. The parasite cunsisted of a lower trunk, a pelvic girdle, and two normal legs. The external genitalia of the parasite presented as a well-formed set of male genitalia with an empty scrotum. The perineum lacked an anal opening. The legs of the parasite did not respond to painful stimuli (Fig 1).

\section{Radiological Examinations}

A plain roentgenogram of the parasite showed an accessory bony pelvis with a well-developed set of lower limbs. No vertebral column was present in the parasite (Fig 2). A barium gastrointestinal study of the autosite showed a normal gastrointestinal tract and no crossover into the gastrointestinal tract of the parasite. Contrastenhanced computed tomography showed a functioning kidney and a bladder in the parasite's pelvis (Fig 3). Echocardiography of the autosite showed a ventricular septal defect (VSD), atrial septal defect (ASD), and patent ductus arteriosus (PDA).

\section{Surgical Separation}

Surgical separation was performed on the seventh day after birth. The parasite was attached to the autosite by skin, subcutaneous tissue, muscle, and fascial layers. The peritoneal cavity of the parasite was connected to that of the autosite. The bowel of the parasite was herniated to the omphalocele of the autosite. Both ends of the parasite's bowel were blind, without any connection to the autosite's gut. The vascular pedicle of the parasite arose from the falciform ligament of the autosite. The autosite's intraperitoneal organs were completely normal in appearance. The parasite had one kidney, which drained via one ureter into his own bladder. The parasite was resected from the autosite without difficulty. The abdominal wall defect and the omphalocele were closed without difficulty, and the postoperative course was satisfactory. Correction of the VSD, ASD, and PDA was performed at 8 months of age. The baby (autosite) is healthy, thriving, and normal (Fig 4).

\section{Chromosome and DNA Studies}

A chromosome study was performed with peripheral blood samples from the autosite and the parasite, using conventional methods. ${ }^{10}$ The karyotypes of both subjects were $46, \mathrm{XY}$ with no evidence of chromosomal aberration. Discrimination of heteropagus zygosity was not possible from the results of chromosome study.

To investigate zygosity, DNA analysis of the heteropagus was performed using the polymerase chain reaction (PCR) technique. Total genomic DNA was prepared from leukocytes of peripheral blood from both the autosite and the parents. The genomic DNA of the parasite was extracted from a paraffin block of kidney tissue from the surgical specimen (parasite).

Haplotyping of the heteropagus and the parents was performed for microsatellites on chromosome $13(\mathrm{Rb} 1.20)$ and chromosome 21(D21S11), which contained tetranucleotide repeats polymorphisms. Primer sequences used to amplify each region were as previously described by Brandt et al and Shamra et al. ${ }^{11,12}$ Haplotyping for D21S11 (Fig 5) and Rb1.20 locus (data not shown) showed that the heteropagus had a monozygotic origin.

\section{DISCUSSION}

Conjoined twinning is one form of duplication or the "doubling anomaly." It ranges from simple super-

From the Departments of Pediatric Surgery and Pediatrics, Yonsei University College of Medicine, Seoul, Korea.

Address reprint requests to Eui IIo IIwang, MD, Department of Pediatric Surgery, Yonsei University College of Medicine, 134 ShinchonDong, Seodaemun-Ku, Seoul 120-752, Korea.

Copyright $\odot 1996$ by W.B. Saunders Company

0022-3468/96/3110-0035\$03.00/0 


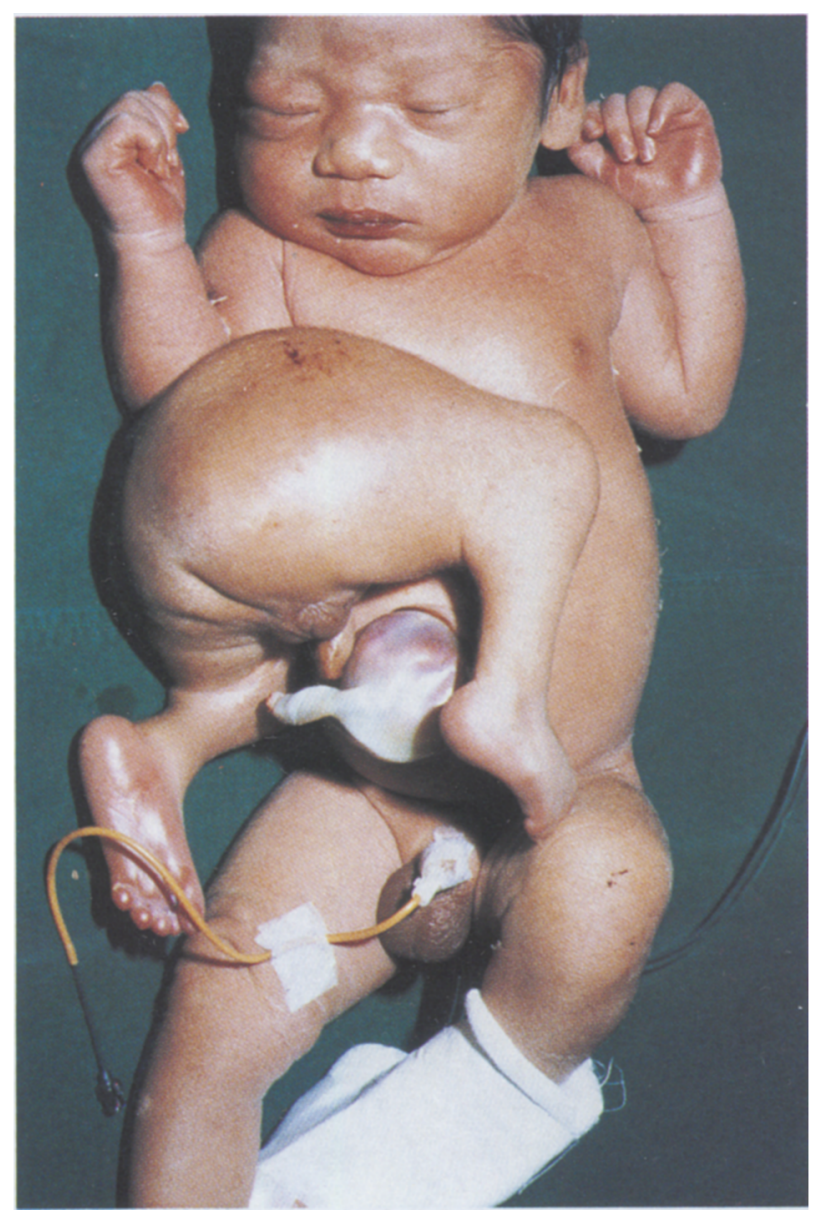

Fig 1. The parasitic twin was attached to the host's epigastrium, above an omphalocele. The parasite had a pelvis with two wellformed legs, a penis, and a scrotum. There was no anal opening in the parasite.

numerary digits and intestinal duplications to the complete or incomplete duplication of an individual. ${ }^{1}$ The exact etiology of conjoined twinning is not known, but the formation of these anomalies is currently believed to be related to incomplete cleavage of the embryo at approximately 2 weeks' gestation. ${ }^{13}$

Twins can originate in two ways. When they originate from two zygotes, they are considered dizygotic twins. When they originate from one zygote, they are referred to as monozygotic twins. About two thirds of twins are dizygotic. Whereas the frequency of dizygotic twinning shows a marked racial difference, the incidence of monorygotic twinning is about the same for all races. The statistically significant tendency for dizygotic twins to repeat in a family leads us to believe that there is a hereditary link, but this is not so with monozygotic twinning. The tendency for binovular twinning appears to be determined by one or more recessive genes that affect the frequency of multiple ovulation. In certain populations, as in Nigerian blacks, the incidence of multiple ovulation and dizygotic twinning is very high. ${ }^{14}$

It is generally assumed that conjoined twins derive from a single blastocyst and represent a form of monozygotic twinning rather than the fusion of dizygotic twins. All studies to date have indicated that conjoined twins are of the same sex, giving strong support to the theory that they are of monozygous derivation.

Through a review of the available literature on previous cases of epigastric heteropagus twins, ${ }^{1-9}$ we found several interesting and differing characteristics relating to epigastric heteropagus cases (Table 1).

1. Conjoined twins are predominantly female, and the cause of the female preponderance is not known. ${ }^{14}$ The reported cases of epigastric heteropagus twins have been male predominant.

2. Hereditary tendency is characteristic of epigastric heteropagus twins. In case 3 (Table 1), the mother has a twin and the father has twin cousins.

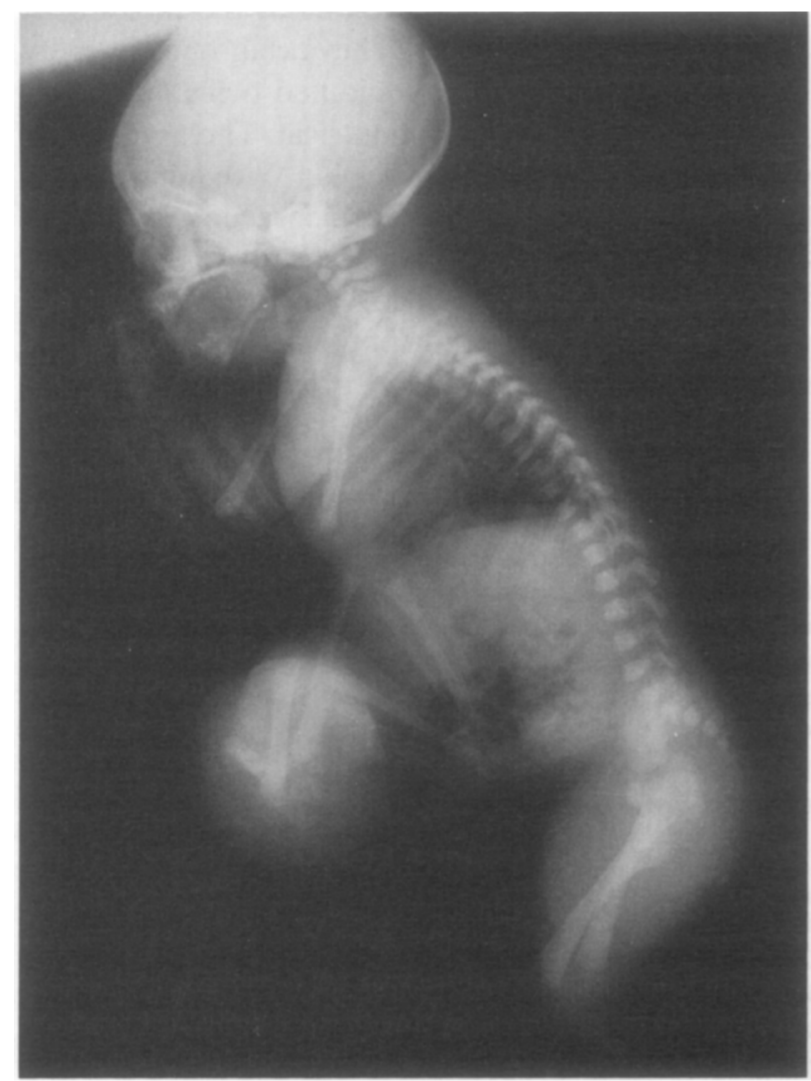

Fig 2. Plain $x$-ray shows the accessory bony pelvis and welldeveloped lower limb bones of the parasite. There was no bony connection between the autosite and the parasite. The parasite did not have a vertebral column. 

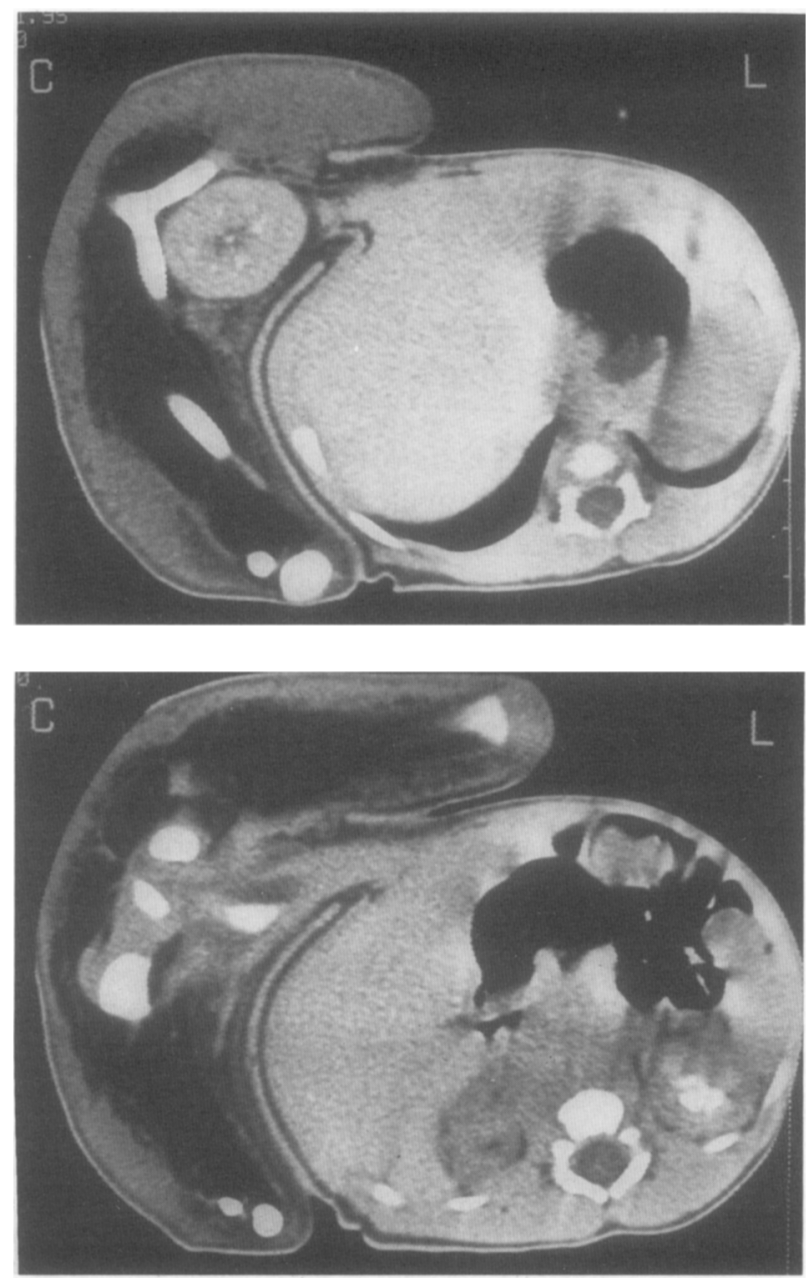

Fig 3. Contrast-enhanced computed tomography scans show a functioning kidney and bladder in the parasite.

The patient is a Nigerian black. This racial population has a higher frequency of twins; they account for $5 \%$ of all births..$^{15}$ In case 7 , the patient has older sisters who are twins. In the present case, the mother's first child had syndactyly, which is a manifestation of the doubling anomaly.

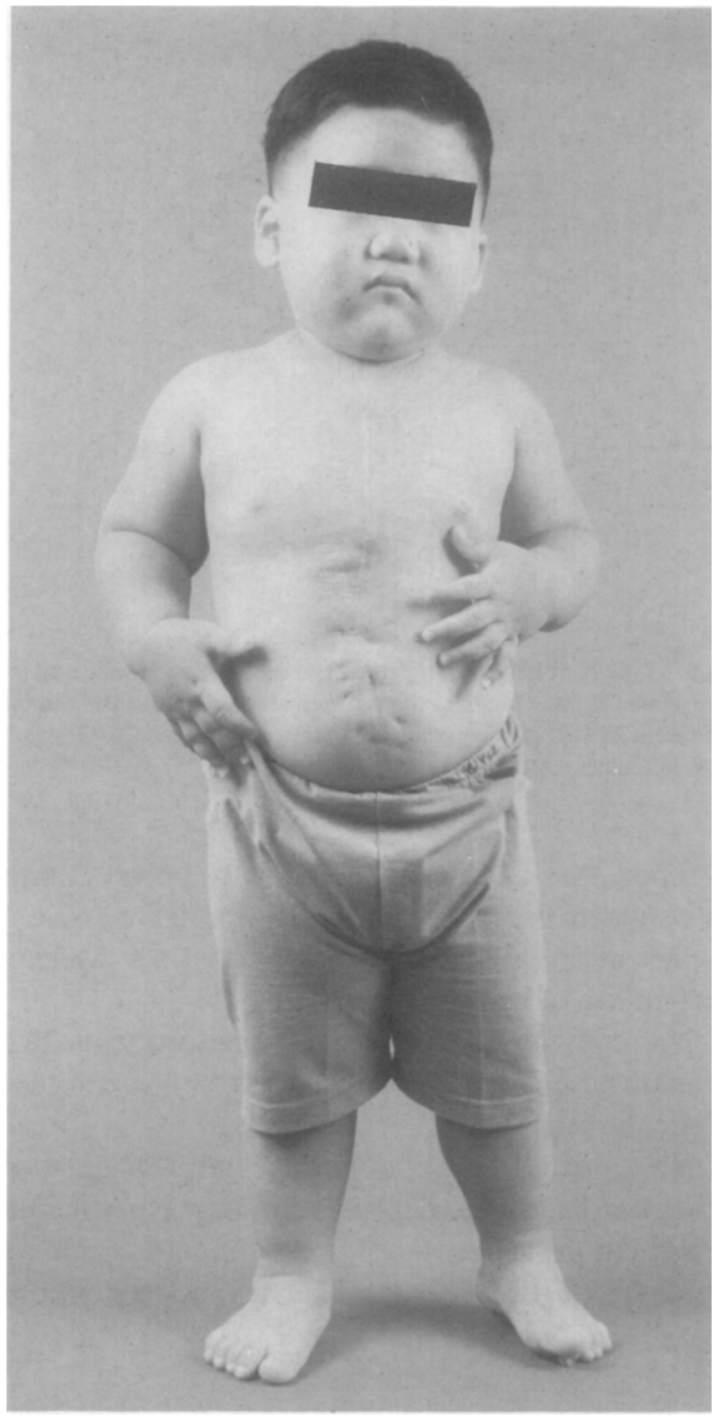

Fig 4. As of June 1995, the 3-year-old boy was healthy and thriving.

Table 1. Summary of Previously Reported Epigastric Heteropagus Cases

\begin{tabular}{|c|c|c|c|c|c|c|c|}
\hline Case & Reference No. & Year & Sex & $\mathrm{FHx}$ & Omphalocele & Bowel Connection/Bone Connection & Vascular Connection \\
\hline 1 & 2 & 1946 & $\mathrm{M}$ & $?$ & - & $-1-$ & ? \\
\hline 2 & 3 & 1969 & $M$ & ? & + & $-1-$ & ? \\
\hline 3 & 4 & 1978 & $F$ & + & - & $-1-$ & $\begin{array}{l}\text { Vascular connection arising from } \\
\text { liver of autosite }\end{array}$ \\
\hline 4 & 9 & 1982 & $\mathrm{~F}$ & $?$ & - & $-1-$ & $\begin{array}{l}\text { Vascular connection arising from } \\
\text { liver of autosite }\end{array}$ \\
\hline 5 & 5 & 1986 & $\mathrm{M}$ & - & + & $\mathrm{Me} /-$ & $?$ \\
\hline 6 & 6 & 1986 & M & - & + & $-1-$ & Two vessels \\
\hline 7 & 7 & 1986 & $\mathrm{M}$ & + & - & $-1-$ & $?$ \\
\hline 8 & 1 & 1988 & $\mathrm{M}$ & $?$ & + & $-1-$ & Left internal mammary artery \\
\hline 9 & 8 & 1993 & $\mathrm{M}$ & - & + & $-1-$ & Epigastric vessel \\
\hline 10 & Present case & 1994 & $\mathrm{M}$ & + & + & $-1-$ & Falciform ligament \\
\hline
\end{tabular}

Abbreviations: $\mathrm{FHx}$, family history of conjoined twins; Me, Meckel's diverticulum. 


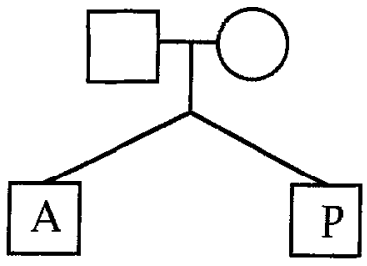

A F M P

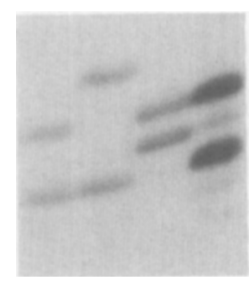

Fig 5. Result of haplotyping for tetranucleotide repeats polymorphism at the D21S11 locus of the patient's family shows the monozygotic origin of this heteropagus condition. $\square$, father $(F) ; O$, mother (M); A, autosite; $P$, parasite.

3. There has been only one case of bowel connection between the autosite and the parasite (case 4); the parasite's bowel was connected to a Meckel's diverticulum of the autosite.

4. No reported case of epigastric heteropagus twins has involved a bony connection between the autosite and the parasite.

5. No reported case of epigastric heteropagus twins has involved a vascular connection between the autosite and the parasite.

In light of the above observations, we initially hypothesized that our epigastric heteropagus case was a dizygotic twin in which a body portion of an embryo fused parasitically to a complete embryo. Previous cytogenetic studies showed an identical, normal karyotype in symmetrically conjoined twins. ${ }^{16}$ However, an identical karyotype is not enough to confirm the monozygotic origin of conjoined twins. Therefore we performed karyotyping and a DNA study. Haplotyping in our case showed a monozygotic origin.

The female zygote is more likely to undergo conjoined twinning than the male, but once formed, male conjoined twins are much less viable and often are aborted. ${ }^{17}$ Among reports of stillborn fetuses of conjoined twins, male gender is predominant. ${ }^{18} \mathrm{~A}$ heteropagus twin could develop when one component is better placed such that it monopolizes the placental blood to the detriment of the other member (parasite) ${ }^{19}$ Epigastric heteropagus twins may result from ischemic atrophy of one part of a monozygotic conjoined twin early in gestational life. This case was the first in which the monozygotic origin of conjoined twins was confirmed by a DNA study. We hope that, in future studies, the surgical specimens of conjoined twins will be analyzed to further confirm the monozygotic origin.

\section{ACKNOWLEDGMENT}

The authors thank Tim Cornish and Carole Shaw for English language revision.

\section{REFERENCES}

1. O'Neill JA Jr, Holcomb GW III, Schnaufer L, et al: Surgical experience with thirteen conjoined twins. Ann Surg 208:299-312, 1988

2. Sarrelangue LP: Surgical specimen of a partially developed parasitic fetus. Arch Surg 52:479-482, 1946

3. Poradowska W, Jaworska $M$, Reszke $S$, et al: Conjoined twins and twin parasites: A clinical analysis of three examples. J Pediatr Surg 4:688-693, 1969

4. Mabogunje OA, Lawrie JH: The heteropagus conjoined twins of NDU Sule, Nigeria. Clin Pediatr 17:861-863, 1978

5. Nasta R, Scibilia G, Corrao A, et al: Surgical treatment of an asymmetric double monstrosity with esophageal atresia, omphalocele, and interventricular defect. J Pediatr Surg 21:60-62, 1986

6. Surendran N, Nainan KM, Paulose MO: An unusual case of caudal duplication. J Pediatr Surg 21:924-925, 1986

7. Pattabiraman C, Krịshna A, Joseph SMJ: Aborted thoracopaguis. Ind J Pediatr 53:531-533, 1986

8. Chadha R, Bagga D, Dhar A, et al: Epigastric heteropagus. J Pediatr Surg 28:723-727, 1993

9. Cywes S, Davies MRQ, Rode H: Conjoined twins-The Red Cross War Memorial Children's Hospital experience. South Afr J Surg 20:105-118, 1982

10. Benn PA, Perle A: Chromosome staining and banding, in
Rooney DE, Czepulkowski BH: Human Cytogenetics. New York, NY, IRL Press, 1992, pp 91-117

11. Brandt B, Greger V, Yandell D, et al: A simple and nonradioactive method for detecting the Rb1.20 DNA polymorphism in the retinoblastoma gene. Am J Hum Genet 51:1450-1451, 1992

12. Shamra V, Litt M: Tetranucleotide repeat polymorphism at the D21S11 locus. Hum Mol Genet 1:67-71, 1992

13. Votteler TP: Conjoined twins, in Welch $\mathrm{KJ}$, Kandolph JG, Ravitch MM, et al: Pediatric Surgery. Chicago, IL, Year Book Medical, 1986, pp 829-836

14. Potter EL, Graig JM: Pathology of the Fetus and the Infant (ed 3). Chicago, IL, Year Book Medical, 1975, pp 207-237

15. Nylander PPS, Corney G: Placentation and zygosity of twin in Ibadab, Nigeria. Ann Hum Genet 33:31-34, 1969

16. Kinl CK, Barr RJ, Benirscluke K: Cytogenetic study of conjoined twins. Obstet Gynecol 38:877-881, 1971

17. Milham S: Symmetrical conjoined twins: An analysis of the birth records of twenty-two sets. J Pediatr 69:643-647, 1966

18. Edmunds LD, Layde PM: Conjoined twins in the United States, 1970-1977. Teratology 25:301-308, 1982

19. Hamilton WJ: A note on the embryology of twinning. Proc $\mathbf{R}$ Soc Med 47:682-685, 1954 